\title{
Selective attention in imprinting '
}

GEORGE MARSH AND GEORGE WALZ

LEHIGH UNIVERSITY

White Leghorn chicks were imprinted to a multidimensional stimulus object at 12-16 h after hatch. At 72-76 $\mathrm{h}$ after hatch the Ss were given preference tests between the imprinted object and a test object differing only in color, form, or size. The imprinted Ss showed a significant preference for the imprinted object only when the imprinted and test objects differed in color. A nonimprinted control group showed no systematic object preferences.

The purpose of the present experiment was to determine the effective stimulus in imprinting. Previous studies have shown that imprinted birds will follow the imprinted object more than a nonimprinted (test) object (Jaynes, 1956), and will show a preference for the imprinted object over a test object in a choice test (Jaynes, 1958; Guiton, 1959; Sluckin \& Taylor, 1964).

In these studies the test and imprinted objects differed simultaneously on several dimensions (e.g., form, color, size) so that it was not possible to determine how much stimulus control was exerted by cues on each dimension. The present experiment was concerned with assessing independently the amount of stimulus control exerted by the cues on each of three dimensions (color, form, and size) following imprinting.

Sluckin (1965, pp. 33-35) has reviewed a number of studies which show that imprinting stimuli differ in their initial preference value. In some previous studies on stimulus control of imprinting (e.g., Jaynes, 1956, 1958), no control group was run to assess such stimulus preferences and, as Grey (1961) points out, the results of these studies are ambiguous. A nonimprinted control group was included in the present study to assess inherent stimulus preferences in the test.

\section{Subjects}

The Ss were 28 newly hatched White Leghorn chicks obtained from a commercial hatchery.

\section{Apparafus}

The apparatus consisted of a rectangular runway, $2 \mathrm{ft} \times 8 \mathrm{ft}$, similar to that used by Jaynes (1956, 1958). The inside of the runway was painted flat white and the only illumination in the room came from a 48 in. fluorescent light mounted $30 \mathrm{in}$. above the apparatus. A motor driven pulley system moved the imprinting object at approximately 3 in. per sec. A tape programmer provided an intermittent movement of the object of $5 \mathrm{sec}$ on and $5 \mathrm{sec}$ off.

The imprinting and test objects differed in shape (cube or sphere), size ( 3 in. or 2 in. in diameter), and color (red or green).

\section{Procedure}

Upon arrival in the laboratory the Ss were housed in visual isolation in individual cubicles. The cubicles were painted flat white. They were continuously illuminated and the temperature was maintained at $98^{\circ} \mathrm{F}$. Fourteen animals were randomly assigned to the experimental and control groups. An imprinting object was selected at random from the eight objects differing in form, color, and size. Approximately 12-16 $\mathrm{h}$ after hatching the $\mathrm{Ss}$ in the experimental group were placed in the apparatus and exposed to the moving imprinting object for $30 \mathrm{~min}$, and then returned to their cubicles. At approximately 72-76 $\mathrm{h}$ after hatching the experimental and control groups were given three preference tests in which the imprinted object and a test object differing only in color, form, or size were presented. In the preference test, the $\mathrm{S}$ was placed midway between the imprinted and test objects, and the objects moved in opposite directions. The amount of time that an $\mathrm{S}$ was within 6 in. of either the imprinted or test object was recorded by the $E$ on two Standard Electric timers accurate to $.01 \mathrm{sec}$. Each preference test lasted $5 \mathrm{~min}$ and the order of running tests for color, form, and size was determined randomly for each $\mathrm{S}$.

\section{Results}

An $F$ test on the total amount of time following in all tests in the experimental and control groups indicated that the imprinting experience significantly increased following in the tests in the experimental group relative to the control group $(F=52.8, \mathrm{df}=1 / 82$, $\mathrm{p}<.001)$.

In order to assess the amount of stimulus control a preference score was computed for each $S$ in each test by subtracting the amount of time spent following the test object from the amount of time spent following the imprinted object. The mean preference scores for the six conditions are shown in Table 1. A 2 by 3 Lindquist Type I analysis of variance (Lindquist, 1953, pp. 267-273) was carried out on the preference scores (with a constant of 2 added to each score to eliminate negative values). The main effect for the experimental vs control conditions was significant $(F=6.48, \mathrm{df}=$ $1 / 26, p<.025$ ). The main effect for dimensions (color, form, and size) was also significant ( $F=8.50, \mathrm{df}=2 / 52$,

Table 1. Mean preferences scores in the test (in $\mathrm{min}$ )

\begin{tabular}{lccl}
\hline \multicolumn{1}{c}{ Group } & \multicolumn{3}{c}{ Dimension } \\
& Color & Forms & Size \\
Experimental & +1.22 & +0.05 & +0.07 \\
Control & +0.05 & +0.02 & -0.26 \\
\hline
\end{tabular}


$\mathrm{p}<.01)$, as was the interaction between the main effects $(\mathrm{F}=4.78$, df $=2 / 52, \mathrm{p}<.025)$. In order to determine the source of the interaction, $F$ tests were run between the preference scores of the experimental and control groups at each of the three dimension conditions. The difference between the experimental and control groups in the preference scores for color was significant $(F=9.34, \mathrm{df}=1 / 26, \mathrm{p}<.001)$. The difference between the experimental and control groups in the form preference scores was not significant $(F<1)$, nor was the difference in the size preference scores significant $(F=1.45, \mathrm{df}=1 / 26, \mathrm{p}>.10)$.

\section{Discussion}

When compared with the relevant control condition, the Ss in the experimental group showed a significant preference for the imprinted object over the test object when the two objects differed only in color. The experimental group did not show any significant preference for the imprinted object when the two objects differed only in form or size.

The present results indicate that when a multidimensional stimulus is presented as an imprinting object only one aspect of the stimulus gains control over the following behavior. The results of the present experiment are consistent with the results obtained by Cofoid \& Honig (1961), which showed that changes in the imprinted object's color produced a stimulus generalization gradient in imprinting. The present results are also similar to results obtained with other species and tasks in which color is found to be a dominant cue. These include studies on stimulus generalization in pigeons (Baron, 1965), discrimination learning in monkeys (Warren, 1953, 1954), and preference tests in young children (Suchman \& Trabasso, 1966).

\section{References}

BARON, M. R. The stimulus, stimulus control and stimulus generalization. In D. I. Mostofsky, (Ed.) Stimulus Generalization. Stanford, Stanford Univ. Press, 1965 (Pp. 62-71).

COFOID, DIANNE A., \& HONIG, W. K. Stimulus generalization in imprinting. Science, 1961, 134, 1692-1694.

GREY, P. H. The releasers of imprinting: differential reactions to color as a function of maturation. J. comp. physiol Psychol, 1961, 54, $597-601$.

GUITON, P. Socialization and imprinting in brown leghorn chicks. Anim. Behav., 1959, 7, 26-34.

JAYNES, J. Imprinting: the interaction of learned and innate behavior: I. Development and generalization. J. comp. physiol. Psychol, 1956, $49,201-206$

JAYNES, J. Imprinting: the interaction of learned and innate behavior: IV. Generalization and emergent discrimination. J. comp. physioh, Psychol, 1958, 51, 238-242.

LINDQUIST, E. F. Design and analysis of experiments in psychology and education. Boston, Houghton Mifflin, 1953.

SLUCKIN, w. Imprinting and early learning. Chicago, Aldine, 1965.

SLUCKIN, W., \& TAYLOR, K. F. Imprinting and short-term retention. Brit. J. of PsychoL, 1964, 55, 181-187.

SUCHMAN, R. G., \& TRABASSO, T. Color and form preference in young children. J. exp. child Psychol, 1966, 3, 177-187.

WARREN, J. M. Additivity of cues in visual pattern discrimination by monkeys. J. comp. physiol Psychol, 1953, 46, 484-486.

WARREN, J. M. Perceptual dominance in discrimination learning by monkeys. J. comp. physiol Psychol, 1954, 47, 290-292.

Note

1. This research was supported in part by United States Public Health Service Grant MH 14154-01 to the first author.

\section{Errarum}

Patten, R.L., \& Rudy, J.W. The Sheffield omission training procedure applied to the conditioning of the licking response in rats. Psychon. Scl., 1967, 8 (11), 463-464-In the third line of the second paragraph, second column, page 363 , the quantity " $35 \mathrm{~dB}$ " should read "74 $\mathrm{dB}$ ( re 0.0002 dynes $/ \mathrm{cm}^{2}$ )." 